\title{
Acolhimento como forma de "Aproximação Científica via Internet" no desenvolvimento de Ambiente Virtual de Aprendizagem: o AVA EspecialiZaida
}

\author{
João Marcelo Rondina*
}

A grande maioria dos alunos hoje navega com naturalidade pela Internet, acessa informaçóes, participa de redes sociais, ouve música e assiste a vídeos online. As escolas e os educadores buscam estabelecer uma conexáo entre estes novos hábitos e os processos de ensino e aprendizagem. Com objetivo de atender a esta demanda, surgiu uma nova categoria de software, o Ambiente Virtual de Aprendizagem (AVA). Trata-se de um tipo de sistema que permite o controle de conteúdos, professores e alunos na condução de cursos e disciplinas através da internet, pois oferece tecnologias que ampliam os limites de tempo e espaço para a realizaçáo de atividades à distância.

Neste contexto, em 2008 desenvolveu-se um AVA para os cursos de Pós-Graduação Lato Sensu em Enfermagem Obstétrica, Enfermagem do Trabalho e Medicina do Trabalho, da Faculdade de Medicina de São José do Rio Preto/SP. O AVA recebeu o nome de EspecialiZaida (www. especializaida.com.br), em homenagem à Profa
Dra Zaida Aurora S.G. Soler, idealizadora do projeto, organizadora e coordenadora geral dos Cursos de Especialização em Enfermagem do Trabalho e Enfermagem Obstétrica e coordenadora gerencial da Especialização em Medicina do Trabalho. Estes cursos são autofinanciáveis e ministrados em parceria com o Centro de Estudos do Departamento de Enfermagem em Saúde Coletiva e Orientação Profissional - CEDESCOP (Enfermagem do Trabalho e Enfermagem Obstétrica) e com a Fundação de Apoio ao Ensino, Pesquisa e Extensão de Serviços à Comunidade da FAMERP (FAEPE).

$\mathrm{Na}$ construção desta solução, observaram-se três dimensóes, propostas por Martin Weller, a saber: Institucional/Tecnológica, Usuário/ Estudante e Acadêmica. Cada uma destas dimensóes possui foco nas principais características que devem ser atendidas pelo AVA: os alunos, a equipe pedagógica e a tecnologia. Para a dimensão tecnológica buscou-se uma plataforma computacional robusta e confiável, a qual pudesse

*Bacharel em Ciências de Computação pela UNESP (IBILCE), Especialista em Administração de Empresas com ênfase em Marketing pela FAAP, Mestre em Engenharia Elétrica pela UNESP (FEIS) e Doutor em Ciências da Saúde (FAMERP), Coordenador do Curso de Pós-Graduação Lato Sensu Tecnologia de Desenvolvimento de Sistemas (Centro Universitário SENAC), Responsável pelo Núcleo de Informática da FAMERP, Chefe da Disciplina Informática do Curso de Medicina da FAMERP, Professor docente do Departamento Epidemiologia e Saúde Coletiva (DESC). Professor do curso de graduação de Medicina e Enfermagem da FAMERP, Professor da Pós-Graduação Lato Sensu da FAMERP, Membro da Sociedade Brasileira de Informática em Saúde (SBIS), site: http://flavors.me/rondina 
atender a centenas de alunos simultaneamente, com qualidade e segurança. Escolheu-se, para implementar o AVA, o sistema Moodle Versão 2.0, cujos usuários contam com a existência de uma grande comunidade, no Brasil e no mundo, composta por programadores de software e educadores, formadora de uma extensa rede de conhecimento.

A dimensão tecnológica, dada a sua importância, deve ser bem planejada, pois a prestaçáo de um serviço desta natureza traz diversos desafios: precisa funcionar dia e noite, sem interrupção; incorporar suporte conteúdos complexos, como vídeos e imagens em alta definição; atender às muitas particularidades dos computadores, tablets e smartphones dos alunos.

$\mathrm{Na}$ extensa tarefa de configuração do AVA, alguns detalhes foram observados, com o objetivo de atender especificamente o profissional da saúde. Destaca-se a influência determinante, e sempre presente no desenvolvimento deste projeto, do conceito de acolhimento, táo próprio ao enfermeiro enquanto cuidador. Essa preocupação foi permeada a todas as açóes empreendidas, a começar pela criaçáo de uma equipe de suporte técnico para atendimento aos alunos e professores. Este grupo é formado por especialistas em computaçáo, que atuam no meio virtual, mas também estão presentes no modo presencial, nos dias de aula, opçáo que permite ao aluno um contato direto com os técnicos do suporte e não somente através de um botão, link ou avatar.

A dimensão pedagógica também foi influenciada pelo conceito de acolhimento: mesmo com a possiblidade de utilização plena do AVA para todas as atividades relacionadas ao curso, mantiveram-se as aulas presenciais e o contato direto com os professores. A metodologia escolhida para dar suporte a esta visão foi a "blended learning", na qual utiliza-se o AVA para complementar os encontros presenciais, direciona-se a ferramenta principalmente para apoio aos alunos, de modo a permitir acesso a conteúdo, informaçóes sobre o curso, troca de mensagens com os professores e a coordenação, além do envio de atividades e arquivos.

Há que se destacar, nestes cenários apresentados, os novos desafios trazidos pelas redes sociais da internet, como, por exemplo, o Twitter e o Facebook. A ampla aceitação destas tecnologias, pelos alunos, motiva a empreender uma maior integração das mesmas com o AVA, cujo resultado é uma maior aproximação junto ao cotidiano das pessoas envolvidas nestes processos. É uma nova perspectiva, que motiva a busca por novas práticas e soluções, com o objetivo de aproveitar todas as oportunidades possíveis de promoção do ensino-aprendizagem via Internet, na área da saúde. Os resultados dos anos de utilização do AVA EspecialiZaida permitem esta conclusão. 